\title{
Xuebijing attenuates hypotension through the upregulation of angiotensin II type 1 receptor-associated protein 1 in rats suffering from heat stroke
}

\author{
ZHIGUO PAN ${ }^{1 *}$, YU SHAO $^{2 *}$, WENPENG DONG $^{3}$, CHENXI LIU $^{4}$, YI CHEN $^{1}$, \\ HUI JIN ${ }^{1}$, LIQUN TANG ${ }^{1}$, JUNMING QIU ${ }^{1}$ and LEI SU ${ }^{1}$
}

Departments of ${ }^{1}$ Intensive Care Unit, ${ }^{2}$ Overseas Chinese and ${ }^{3}$ Cardiovascular Surgery, and ${ }^{4}$ Information Center, Guangzhou General Hospital of Guangzhou Military Command, Guangzhou, Guangdong 510010, P.R. China

Received April 5, 2014; Accepted September 12, 2014

DOI: $10.3892 /$ ijmm.2014.1950

\begin{abstract}
In our previous study, we demonstrated that Xuebijing (XBJ), a traditional Chinese medicine, attenuates hypotension in rats suffering from heatstroke (HS). However, the underlying mechanisms have not yet been fully elucidated. Thus, the current study was carried out to investigate the mechanisms underlying the effects of XBJ on hypotension $n$ rats suffering from HS. For this purpose, 72 anesthetized rats were randomized into 3 groups and intravenously injected twice daily for 3 days with XBJ ( $4 \mathrm{ml} / \mathrm{kg}$ body weight, XBJ group) or phosphate-buffered saline (PBS) (HS and shamoperated groups). Models of HS were established in the HS and XBJ groups by placing the rats in a simulated climate chamber with a temperature of $40^{\circ} \mathrm{C}$ and a humidity of $60 \%$. Rectal temperature, arterial pressure and heart rate were monitored and recorded. Angiotensin II (Ang II) levels were increased during HS (shown by ELISA), and XBJ had no apparent effect on Ang II levels. The levels of Ang II type 1 (AT1) receptor surface expression and AT1 receptor-associated protein 1 (Arap1) were decreased during HS; however, these effects were attenuated by pre-treatment with XBJ (shown by RT-qPCR and western blot analysis). For in vitro experiments, rat macrophages pre-treated with $\mathrm{XBJ}$ were stimulated with
\end{abstract}

Correspondence to: Dr Lei Su, Department of Intensive Care Unit, Guangzhou General Hospital of Guangzhou Military Command, No. 111 Liuhua Road, Guangzhou, Guangdong 510010, P.R. China E-mail: leisu_icu@163.com

${ }^{*}$ Contributed equally

Abbreviations: HS, heat stroke; XBJ, Xuebijing; Ang II, angiotensin II; AT1, angiotensin II type 1; Arap1, angiotensin II type 1 receptorassociated protein 1 ; NF- $\kappa \mathrm{B}$, nuclear factor $\kappa \mathrm{B}$; IL, interleukin; TNF, tumor necrosis factor; IFN, interferon; LPS, lipopolysaccharide

Key words: heat stroke, angiotensin II type 1 receptor, angiotensin II type 1 receptor-associated protein 1 , inflammation, nuclear factor $\kappa \mathrm{B}$, Xuebijing lipopolysaccharide (LPS). Pre-treatment with XBJ induced a marked inhibitory effect on the release of pro-inflammatory cytokines in the LPS-stimulated macrophages. Furthermore, XBJ inhibited the activation of nuclear factor $\kappa \mathrm{B}(\mathrm{NF}-\kappa \mathrm{B})$ induced by LPS in the macrophages. Taken together, our data demonstrate that XBJ promotes Arap1 expression by inhibiting the activation of the NF- $\kappa \mathrm{B}$ signaling pathway and the release of pro-inflammatory cytokines, which may be the molecular mechanisms through which XBJ alleviates blood pressure reduction in rats suffering from HS.

\section{Introduction}

Exposure to high environmental temperatures or whilst carrying out strenuous work frequently leads to heat stroke (HS), which is a life-threatening illness that is clinically characterized by a high core temperature $\left(>40^{\circ} \mathrm{C}\right)$ and dysfunction of the central nervous system, including delirium, seizures and coma (1). HS is considered one of the most deadly natural hazards with a high morbidity and mortality rate during heat waves $(2,3)$. Aggressive clinical therapies, including rapid cooling, fluid resuscitation to stabilize organ function and supportive treatments, have been applied in the treatment of HS; however, there is still a lack of proper diagnosis and treatment approaches. Currently, there is an urgent need to develop effective clinical therapeutics.

To date, knowledge of the pathology of HS is still poorly understood. The pathology of HS has been suggested to be associated with multiple organ dysfunction syndrome and systemic inflammatory response syndrome (4). Heat stress causes gut epithelial barrier damage, resulting in bacteria and/or endotoxin leakage into the circulation, which initiates excessive inflammation and subsequent cytokine secretion $(5,6)$. Cytokines, key regulators of inflammation, have been suggested to account for systemic inflammatory response syndrome in HS (4). Clinical investigations have revealed that circulating levels of interleukin (IL)-1, tumor necrosis factor (TNF) $\alpha$, interferon (IFN) $\gamma$, IL-6, IL-10 and corresponding receptors are elevated in patients with HS (7-10). In an animal model of HS, plasma concentrations of IL-1, IL- 6 and IL-10 were also found to be upregulated with the increasing core temperature (4). Multiple 
organ dysfunction has been suggested to occur due to heat cytotoxicity, coagulopathies and systemic inflammation (11). Hyperthermia has been suggested to be associated with arterial hypotension (12). Certain studies have demonstrated that the inhibition of the IL-1 receptor by receptor antagonists can attenuate arterial hypotension in HS $(13,14)$.

The renin-angiotensin system plays an important role in regulating blood pressure (15). Heat stress can induce the activation of the renin-angiotensin system to synthesize angiotensin II (Ang II), a type of vasoconstrictor, which engages Ang II type 1 (AT1) receptors to promote blood pressure (16). In some conditions such as sepsis, although Ang II concentrations are elevated, blood pressure still decreases due to the desensitized receptor $(16,17)$. Receptor insensitivity may be caused by the inhibition of receptor transcription, translation and/or membrane trafficking $(18,19)$. Previous studies have identified AT1 receptor-associated protein 1 (Arap1) as the most relevant mediator of AT1 receptor sensitivity, which binds to AT1 receptors and regulates AT1 receptor internalization, membrane re-trafficking and receptor sensitivity $(20,21)$. It has also been demonstrated that the suppression of Arap1 contributes to the development of hypotension during sepsis (22).

In our previous study, we demonstrated that the injection of Xuebijing (XBJ) alleviated HS-induced arterial hypotension (23). However, the underlying mechanisms have not been yet been fully elucidated. XBJ injection is a traditional Chinese compound preparation combining safflower yellow A, tetramethylpyrazine, Danshensu and ferrulic acid, which has been shown to exert protective effects against sepsis (24). In the current study, we aimed to explore the underlying mechanisms of XBJ in alleviating HS-induced arterial hypotension. Using a rat model of HS, we found that the surface expression of AT1 receptor was markedly decreased and that Arap1 expression was also suppressed during HS; these effects were attenuated by pre-treatment with XBJ. In addition, we used a cell model [rat macrophages stimulated with lipopolysaccharide (LPS)] to mimic endotoxin leakage into the circulation to initiate inflammation. Pre-treatment with XBJ inhibited the release of pro-inflammatory pro-inflammatory cytokines, including IL-1 $\beta$ and $\mathrm{TNF} \alpha$, in the LPS-stimulated macrophages. Furthermore, our results revealed that XBJ was inhibited the activation of the nuclear factor $\kappa \mathrm{B}(\mathrm{NF}-\kappa \mathrm{B})$ signaling pathway, which is responsible for promoting pro-inflammatory cytokine expression induced by LPS. Considering the inhibitory effect of pro-inflammatory cytokines on Arap1 expression (22), and taking our data into account, it can be concluded that XBJ upregulates Arap1 expression by inhibiting the activation of the $\mathrm{NF}-\kappa \mathrm{B}$ signaling pathway, which alleviates blood pressure reduction in rats suffering from $\mathrm{HS}$.

\section{Materials and methods}

Experimental animals and ethics statement. Due to the effects of estrogen on HS (25), 72 male adult (25-week-old) pathogen-free Wistar rats (weighing 250-220 g) purchased from the Experimental Animal Center of the Guangzhou General Hospital of Guangzhou Military Command (Animal Quality Certification No. SCXK2006-0015, Guangzhou, China) were used in this study. The rats were housed in an environment of $25 \pm 0.5^{\circ} \mathrm{C}$ with $35 \pm 5 \%$ humidity in individual wire hanging cages with a normal light-dark cycle $(14: 10 \mathrm{~h}$; 06:00-20:00 light cycle and 20:00-06:00 dark cycle) and were allowed free access to food and water. Prior to each experiment, the rats were allowed to adapt to the new living environment for at least 2 weeks. This study was carried out in strict accordance with the guidelines of the National Health and Medical Research Council for the Care and Use of Animals for Experimental Purposes in China. The protocol was approved by the Institutional Animal Care and Use Committee of Guangzhou General Hospital of Guangzhou Military Command.

Cell culture. A rat macrophage cell line (RMa-bm) obtained from ScienCell (Carlsbad, CA, USA) was cultured in macrophage medium (MaM) (Cat. No. 1921) according to the manufacturer's instructions (ScienCell) and maintained at $37^{\circ} \mathrm{C}$ in $5 \%$ carbon dioxide $\left(\mathrm{CO}_{2}\right)$-enriched air in a cell incubator (HF90; Healforce, Shanghai, China).

Study design and animal model preparation. After the rats were allowed to acclimatize for 2 weeks at an ambient temperature $\left(25 \pm 0.5^{\circ} \mathrm{C}\right)$ and humidity $(35 \pm 5 \%)$, the 72 rats were randomly divided into 3 groups. Prior to the induction of HS, 2 groups of rats ( $n=24 /$ group) were intravenously injected with phosphate-buffered saline (PBS) (4 ml/kg body weight) twice daily for 3 days through the tail vein, and another group $(n=24)$ was intravenously injected with XBJ ( $4 \mathrm{ml} / \mathrm{kg}$ body weight; Chinese medicine accurate character Z20040033; Chase Sun Pharmaceutical Co., Ltd., Tianjin, China) twice daily for 3 days, as previously described (23). For the HS modelestab, the rats were generally anesthetized with pentobarbital sodium (50 mg/kg; Merck KGaA, Darmstadt, Germany) by intraperitoneal injection to abolish corneal and pain reflexes and to minimize their suffering. A trocar $(24 \mathrm{G})$ was cannulated in the right femoral artery of each rat to monitor mean arterial pressure (MAP). The rats in the group pre-treated with PBS $(n=24)$ and the group pre-treated with XBJ $(n=24)$ were placed in an incubator with a stable temperature $\left(40.0 \pm 0.5^{\circ} \mathrm{C}\right)$ and relative humidity $(60 \pm 5 \%)$; these groups were termed the HS group and XBJ group, respectively. The rats in the group pre-treated with PBS $(\mathrm{n}=24)$ were exposed to a temperature of $25 \pm 0.5^{\circ} \mathrm{C}$ with a humidity of $35 \pm 5 \%$; this was used as the sham-operated group. A multi-parameter Physiological Monitor (Infinity ${ }^{\circledR}$ Delta XL; Dräger, Lübeck, Germany) was used to monitor rectal temperature (Tc) at intervals of $10 \mathrm{~min}$. When the MAP decreased by $25 \mathrm{mmHg}$ and the core temperature was $>42^{\circ} \mathrm{C}$, the rats were withdrawn from the chamber, as previously described (26).

Detection of Ang II expression in myocardial tissue and serum. During the preparation of the model of HS, 8 rats from each group were randomly selected at 30,60 and $90 \mathrm{~min}$ for the measurement of Ang II expression. Blood samples were collected through the orbital vein and serum was separated by centrifugation and stored at $-80^{\circ} \mathrm{C}$. Following blood collection, the chests of the rats were opened immediately and the hearts were excised. Left ventricular myocardial tissue was isolated and weighed. A total of $100 \mathrm{mg}$ myocardial tissues was collected and boiled in $1 \mathrm{ml}$ of acetic acid $(0.5 \mathrm{mM})$ for $10 \mathrm{~min}$. The tissues were cut into sections and homogenized under 
ice-cold conditions followed by centrifugation $(12,000 \mathrm{rpm})$ at $4^{\circ} \mathrm{C}$ for $20 \mathrm{~min}$. The supernatants were then collected for analysis. Ang II levels in the myocardial tissue or serum were determined using the rat Ang II ELISA kit (Biorbyt Ltd., Cambridge, UK) according to standard protocols.

Cell stimulation. The rat macrophages were pre-treated with XBJ at concentrations of 10,25 , or $50 \mathrm{mg} / \mathrm{ml}$ for $24 \mathrm{~h}$. Subsequently, LPS (10 mg/ml; Sigma, St. Louis, MO, USA) was added followed by incubation for $24 \mathrm{~h}$. Total cell RNA or protein was harvested according to standard protocols for further analysis.

Quantitative reverse transcription PCR (RTqPCR). Total RNA was extracted from the right common carotid arteries of the rats or from the cells using TRIzol reagent (Invitrogen, Carlsbad, CA, USA) and $5 \mu \mathrm{g}$ of total RNA were reverse-transcribed into cDNA using M-MLV reverse transcriptase (Clontech, Palo Alto, CA, USA). cDNA was used as the template for RT-qPCR. For rat Arap1, the sense primer was 5'-ccagaaagcgagtactataagctgc-3' and the antisense primer was 5'-cttaatggaaagtgttggggttgg-3'. Rat GAPDH primers (sense, 5'-acagcaacagggtggtggac-3' and antisense, 5'-tttgagggtgcagcgaactt-3') were used as the controls. The RT-qPCR mixture system contained $5 \mu \mathrm{l} \mathrm{SsoFast}{ }^{\mathrm{TM}}$ EvaGreen Supermix (Bio-Rad, Hercules, CA, USA), $1 \mu \mathrm{l}$ of cDNA (diluted in 1:50) and $2 \mu \mathrm{l}$ of each of the forward and reverse primers $(1 \mu \mathrm{M})$ to a final volume of $10 \mu$. The PCR procedure was as follows: $94^{\circ} \mathrm{C}$ for $4 \mathrm{~min} ; 94^{\circ} \mathrm{C}$ for $20 \mathrm{sec}$, $55^{\circ} \mathrm{C}$ for $30 \mathrm{sec}$ and $72^{\circ} \mathrm{C}$ for $20 \mathrm{sec} ; 2 \mathrm{sec}$ for plate reading for 35 cycles; and melting curve from 65 to $95^{\circ} \mathrm{C}$. GAPDH was used as the control for normalizing gene expression. Three independent experiments were performed. The data obtained were calculated using the $2^{-\Delta \Delta C t}$ method and statistical analysis was carried out as previously described (27), followed by an unpaired sample t-test.

Membrane protein and nuclear protein isolation. Membrane protein was isolated using the Membrane Protein Extraction kit (Sangon, Shanghai, China) as per the manufacturer's instructions. Briefly, the cells or tissues $(200 \mathrm{mg}$, cut into small sections) were washed with wash buffer at least 3 times. Subsequently, $1 \mathrm{ml}$ of extract buffer containing DTT $(1 \mu \mathrm{g} / \mathrm{ml})$ was added and homogenized under ice-cold conditions followed by centrifugation $(14,000 \mathrm{rpm})$ at $4^{\circ} \mathrm{C}$ for $10 \mathrm{~min}$. The supernatants were collected, bathed at $37^{\circ} \mathrm{C}$ for $10 \mathrm{~min}$, and then centrifuged $(13,000 \mathrm{rpm})$ at room temperature for $5 \mathrm{~min}$. The samples were divided into 2 layers: the upper layer containing cytoplasmic proteins was collected and the bottom layer containing membrane proteins was dissolved in $500 \mu \mathrm{l}$ of ice-cold sterile water for $5 \mathrm{~min}$ at $4^{\circ} \mathrm{C}$ followed by incubation in a water bath at $37^{\circ} \mathrm{C}$ for $5 \mathrm{~min}$. Following centrifugation $(13,000 \mathrm{rpm})$ at room temperature for $5 \mathrm{~min}$, the bottom layer was collected and dissolved in ice-cold sterile water again following the above steps. Finally, the membrane extracts were collected and the protein concentration was measured using the BCA kit (Pierce Biotechnology, Inc., Rockford, IL, USA). For SDS-PAGE, a total of $100 \mu 1$ membrane protein was mixed with $0.9 \mathrm{ml}$ acetone, and incubated under ice-cold conditions for $20 \mathrm{~min}$ followed by centrifugation $(10,000 \mathrm{rpm}$ ) for $20 \mathrm{~min}$. The supernatants were removed, and $100 \mu \mathrm{l}$ of loading buffer and $2 \mu \mathrm{l}$ of $\beta$-mercaptoethanol were added to dissolve the sediments for SDS-PAGE. Nuclear proteins were extracted using an extraction kit (Sangon) according to the manufacturer's instructions. Briefly, the cells were lysed in cytoplasmic buffer containing protease inhibitors, mixed and incubated for $15 \mathrm{~min}$ at $4^{\circ} \mathrm{C}$, followed by centrifugation at $12,000 \mathrm{rpm}$ for $20 \mathrm{~min}$ at $4^{\circ} \mathrm{C}$. Cell sediments were collected and were resuspended in nuclear buffer for $10 \mathrm{~min}$ at $4^{\circ} \mathrm{C}$. The sample was then centrifuged at $12,000 \mathrm{rpm}$ for $10 \mathrm{~min}$ at $4^{\circ} \mathrm{C}$. The supernatant containing nuclear proteins was collected for analysis.

Western blot analysis. Proteins separated by $12 \%$ SDS-PAGE were electrotransferred onto a nitrocellulose membrane (Amersham, Little Chalfont, UK). The membrane was then incubated with $2 \%$ non-fat dry milk in Tris-buffered saline (TBS) to block non-specific binding at room temperature for $1 \mathrm{~h}$. Subsequently, the membrane was incubated with the following primary antibodies: rabbit anti-rat AT1 receptor polyclonal IgG $(1: 1,000)$ antibody, goat anti-rat Arap1 polyclonal IgG (1:1,000; both from Abcam, Cambridge, UK), goat anti-rat Histone polyclonal IgG (1:1,000; Santa Cruz Biotechnology, Inc., Santa Cruz, CA, USA) rabbit anti-rat NF-кB p65 polyclonal IgG (1:1,000; Santa Cruz Biotechnology, Inc.), goat anti-rat $\mathrm{I} \kappa \mathrm{B} \alpha$ and $\mathrm{p}-\mathrm{I} \kappa \mathrm{B} \alpha$ monoclonal $\operatorname{IgG}(1: 2,000$; Cell Signaling Technology, Inc., Boston, MA, USA), rabbit anti-rat GAPDH polyclonal IgG and caveolin-1 (1:1,000; Abcam) antibody diluted in blocking buffer overnight at $4^{\circ} \mathrm{C}$. Subsequently, the membrane was incubated in horseradish peroxidase (HRP)-conjugated goat anti-rabbit IgG or rabbit anti-goat IgG (Boster Biological Technology Co., Ltd, Wuhan, China) diluted in blocking buffer according to the corresponding primary antibodies for $1 \mathrm{~h}$. Finally, 4-chloro-1-naphthol (4-CN) as an HRP substrate was used for protein visualization. The protein gray intensity was detected by using BandScan 0.5 software (ProZyme, San Leandro, CA, USA).

Statistical analysis. Data are expressed as the means \pm standard deviation (SD). The statistical significance of differences between 2 groups was determined by the Student's t-test, and differences among multiple groups were determined by one-way ANOVA. A value of $\mathrm{P}<0.05$ was considered to indicate a statistically significant difference. All statistical analyses were performed using SPSS version 11.5 software (SPSS Inc., Chicago, IL, USA).

\section{Results}

XBJ has no effect on Ang II levels following during HS. A previous study (12) revealed that arterial hypotension occurs during HS. In our previous data (23), we demonstrated that XBJ alleviated the decrease in MAP during HS in a rat model. Ang II, a type of vasoconstrictor, increases blood pressure (16). In this study, in order to investigate the levels of Ang II in rats during $\mathrm{HS}$ and the effects of XBJ on Ang II, we evaluated Ang II levels in serum or myocardial tissue. The results revealed that the serum levels of Ang II in the HS or XBJ groups were markedly increased compared with those in the sham-operated group at 30,60 and $90 \mathrm{~min}(\mathrm{p}<0.05)$ (Fig. 1A). However, there was no significant difference in the serum levels of Ang II between the HS and XBJ groups. Furthermore, 

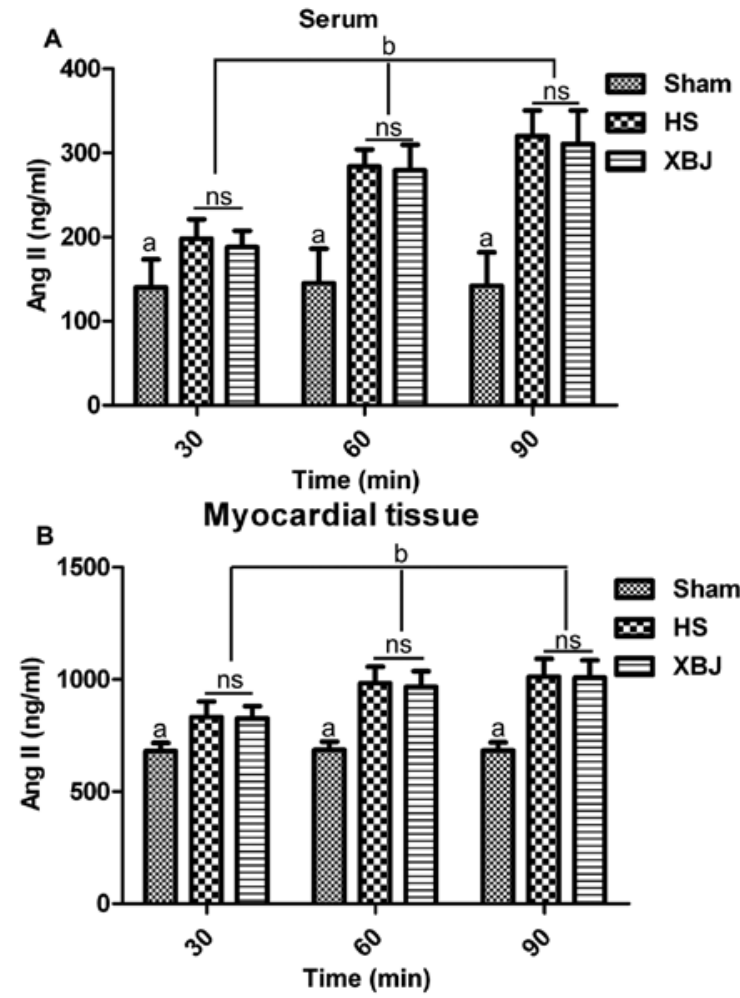

Figure 1. Detection of angiotensin II (Ang II) levels in a rat model of heat stroke (HS). Ang II levels in (A) serum and (B) myocardial tissue were analyzed by ELISA. Sham, sham-operated rats pre-treated with phosphate-buffered saline (PBS) under normal conditions used as controls; HS, rats pre-treated with PBS pre-treatment HS conditions; Xuebijing (XBJ), rats pre-treated with XBJ under HS conditions. Rat serum or myocardial tissue were collected at 30,60 and 90 min post-treatment. ${ }^{a} \mathrm{p}<0.05$, comparison of sham-operated vs. HS or XBJ groups; ${ }^{\mathrm{b}} \mathrm{p}<0.05$, comparison of 30 vs. $60 \mathrm{~min}$ or $90 \mathrm{~min}$ in the HS or XBJ groups; ns, no significant differences between the HS and XBJ groups.

the Ang II serum levels increased from 30 to $90 \mathrm{~min}$ in the HS and XBJ groups in a time-dependent manner $(\mathrm{p}<0.05)$, while the Ang II levels remained stable in the sham-operated group (Fig. 1A). Similar results were obtained in the myocardial tissue (Fig. 1B). These data indicated that the Ang II levels were upregulated during HS, and that pre-treatment with XBJ had no obvious effect on the Ang II levels in the rats suffering from HS. Therefore, it is intriguing that the arterial pressure still decreased as shown in our previous study (23) during HS, while the Ang II levels increased. However, our previous data (23) demonstrated that pre-treatment with XBJ still attenuated hypotension. Collectively, our data indicated that XBJ alleviated the decrease in blood pressure and that this decrease was independent of the Ang II levels in the rats suffering from HS.

$X B J$ accelerates AT1 receptor trafficking to the membrane. The Ang II levels were increased during HS; however, blood pressure was still downregulated. We hypothesized that Ang II signal transduction is inhibited during HS. In order to examine our hypothesis, we analyzed the Ang II corresponding receptor, AT1 receptor, which has been suggested to be desensitized by elevated levels of Ang II $(16,17,28)$. Hence, we detected the membrane and cytoplasmic levels of the AT1 receptor in arterial tissue. The results revealed that AT1 receptor membrane expression was decreased by $66.4 \%$

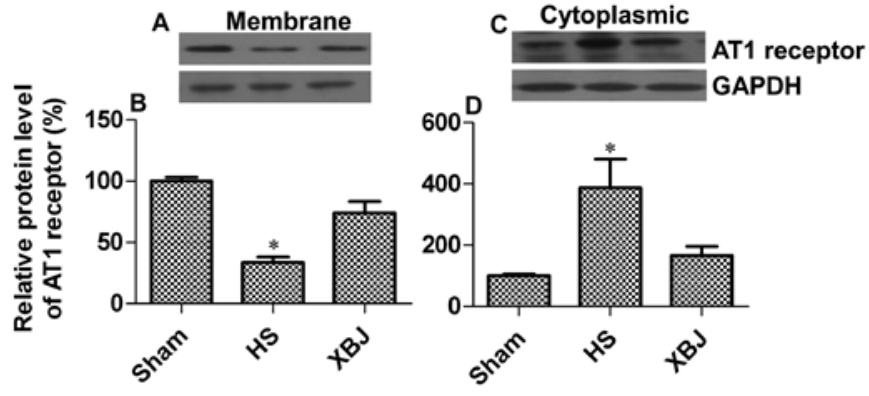

Figure 2. Effects of Xuebijing (XBJ) on angiotensin II type 1 (AT1) receptor trafficking. (A) Analysis of AT1 receptor membrane expression by western blot analysis. (B) Relative quantification of AT1 receptor protein membrane expression normalized to caveolin-1 using BandScan 5.0 software. (C) Analysis of AT1 receptor cytoplasmic expression by western blot analysis. (D) Relative quantification of AT1 receptor protein cytoplasmic expression normalized to GAPDH. Caveolin-1 was used as the internal control of the membrane protein. GAPDH was used as internal control of the cytoplasmic protein. The experiment was performed using tissues from the left common carotid artery of the rats. The data are presented as the means \pm standard deviation (SD) from 3 samples and 3 independent experiments. " $\mathrm{P}<0.05$ compared to the other groups. Sham, shamoperated rats pre-treated with phosphate-buffered saline (PBS) under normal conditions used as controls; HS, rats pre-treated with PBS pre-treatment HS conditions; XBJ, rats pre-treated with XBJ under HS conditions.

in the HS group in comparison with the sham-operated group, while pre-treatment with XBJ increased AT1 receptor membrane expression by $40.3 \%$ when compared with the HS group ( $\mathrm{p}=0.0437$ ) (Fig. 2A and B). There was a significant accumulation of cytoplasmic AT1 receptor (3.9-fold increase) in the HS group as compared with the sham-operated group, while pre-treatment with XBJ markedly attentuated this effect (57.4\% decrease; $p=0.0202$ ) (Fig. $2 \mathrm{C}$ and $\mathrm{D}$ ). These data suggest that pre-treatment with XBJ promotes AT1 receptor surface expression.

$X B J$ increases AT1 receptor surface expression through the upregulation of Arap1. Arap1 has been suggested as the most relevant mediator of AT1 receptor trafficking to the cell membrane $(20,21)$; therefore, we wished to investigate whether Arap1 expression is altered during HS and the effects of XBJ on Arap1 expression. The results from RT-qPCR indicated that the Arap1 transcription levels in the HS group were significantly decreased by $77.6 \%$ compared with the sham-operated group (Fig. 3A). These results were confirmed by western blot analysis (decrease of $61.4 \%$; $\mathrm{p}=0.0132$ ) (Fig. 3B and C). This may explain why hypotension still occurs while Ang II levels increase during HS. We also hypothesized that XBJ positively regulates Arap1 expression. As expected, pre-treatment with XBJ attenuated the effects of HS on Arap1 expression, indicating that XBJ accelerated Ang II signal transduction through the upregulation of Arap1.

$X B J$ inhibits the secretion of pro-inflammatory cytokines in macrophages in vitro. The main hazard of heat stress is dysregulated intestinal permeability leading to the translocation of bacteria and endotoxins into the circulation, which then results in a dramatic inflammatory response and cytokine secretion $(5,6)$. Pro-inflammatory cytokines have been shown to have an inhibitory effect on Arap1 expression (22). Our previous study demonstrated that pre-treatment with 


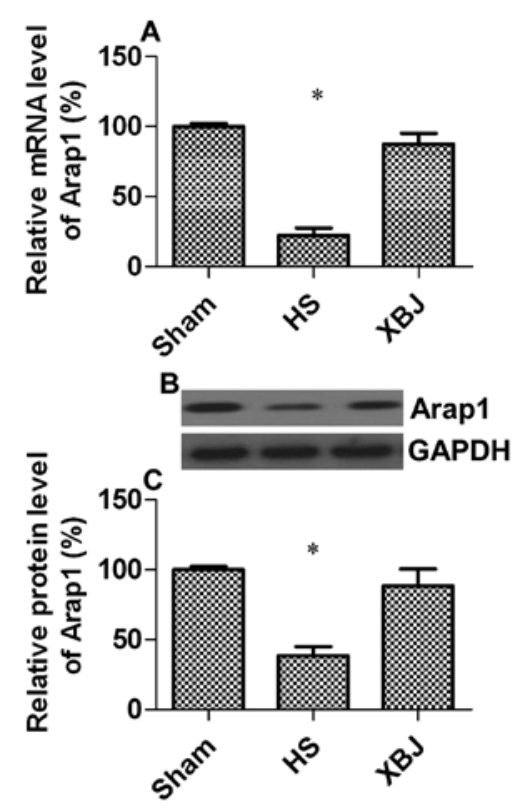

Figure 3. Effects of Xuebijing (XBJ) on angiotensin II type 1 receptor associated protein 1 (Arap1) expression. Analysis of Arap1 (A) mRNA and (B) protein expression by RT-qPCR and western blot analysis, respectively. (C) Relative quantitative analysis of Arap1 protein expression normalized to GAPDH. The experiment was performed using tissues from the left common carotid artery of the rats. The data are presented as the means \pm standard deviation (SD) from 3 samples and 3 independent experiments. ${ }^{*} \mathrm{P}<0.05$ compared to the other groups. Sham, sham-operated rats pre-treated with phosphate-buffered saline (PBS) under normal conditions used as controls; HS, rats pre-treated with PBS pre-treatment HS conditions; XBJ, rats pretreated with XBJ under HS conditions.
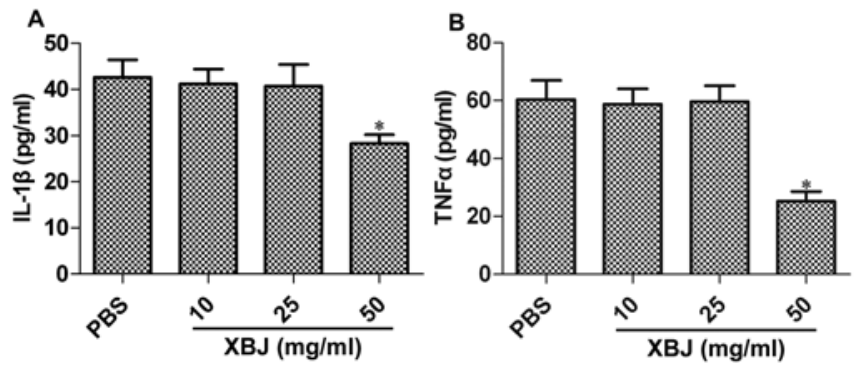

Figure 4. Effects of Xuebijing (XBJ) on the secretion of pro-inflammatory cytokine in lipopolysaccharide (LPS)-stimulated macrophages. Levels of (A) interleukin (IL)-1 $\beta$ and (B) tumor necrosis factor (TNF) $\alpha$ in cell culture supernatants were measured by ELISA according to the manufacturer's instructions. Macrophages were pre-treated with XBJ at concentrations of 10,25 , or $50 \mathrm{mg} / \mathrm{ml}$ for $24 \mathrm{~h}$. Cells pre-treated with phosphate-buffered saline (PBS) used as controls. LPS $(10 \mathrm{mg} / \mathrm{ml})$ was then added followed by incubation for $12 \mathrm{~h} . \mathrm{N}=6,{ }^{*} \mathrm{p}<0.05$ compared with the control group.

XBJ has an inhibitory effect on pro-inflammatory cytokine secretion in a rat model of HS (23). In this study, we wished to investigate whether XBJ inhibits cytokine expression in an in vitro cell model. Rat macrophages were pre-treated with XBJ at concentrations of 10,25 and $50 \mathrm{mg} / \mathrm{ml}$, and then stimulated with LPS; the levels of IL- $1 \beta$ or TNF $\alpha$ were then determined. The results revealed that the XBJ concentration of $50 \mathrm{mg} / \mathrm{ml}$ resulted in a significant decrease in the IL-1 $\beta$ levels by $33.6 \%(p=0.0308$; Fig. $4 \mathrm{~A})$ and in the TNF $\alpha$ levels by $58.2 \%$ ( $p=0.0237$; Fig. 4B). However, XBJ at concentra-

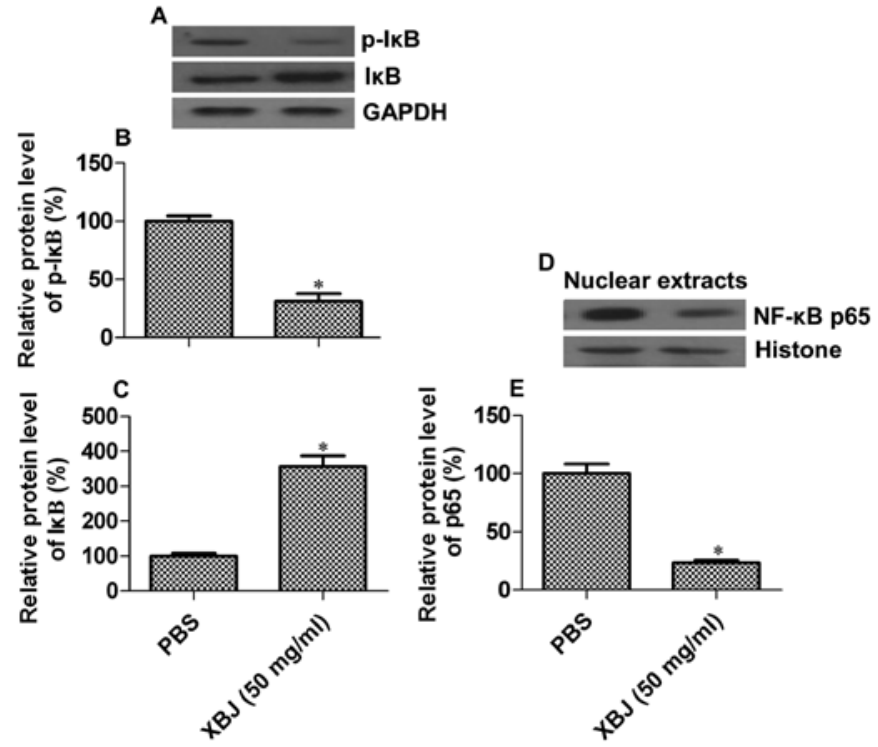

Figure 5. Effects of Xuebijing (XBJ) on the activation of the nuclear factor $\kappa \mathrm{B}(\mathrm{NF}-\kappa \mathrm{B})$ signaling pathway. Cells were pre-treated with XBJ (50 mg/ $\mathrm{ml}$ ) for $24 \mathrm{~h}$, while phosphate-buffered saline (PBS) was used as a control. Lipopolysaccharide (LPS) $(10 \mathrm{mg} / \mathrm{ml})$ was then added followed by incubation for $12 \mathrm{~h}$. Total cell extracts or nuclear extracts were prepared. (A) The phosphorylated $\mathrm{I} \kappa \mathrm{B}$ and $\mathrm{I} \kappa \mathrm{B}$ protein levels were determined by western blot analysis. Relative quantitative analysis of (B) phosphorylated I $\mathrm{B}$ and $(\mathrm{C}) \mathrm{I} \kappa \mathrm{B}$ protein levels were normalized to GAPDH. (D) NF- $\mathrm{BB}$ p65 protein level in the nucleus is shown. Histone was used as a control of nuclear proteins. (E) Relative quantitative analysis of NF- $\mathrm{NB}$ p65 protein level was normalized to histone. $\mathrm{N}=3,{ }^{*} \mathrm{p}<0.05$ compared to control group.

tions of 10 and $25 \mathrm{mg} / \mathrm{ml}$ had no effect on the release of pro-inflammatory cytokines ( $\mathrm{p}>0.05$; Fig. 4 ).

$X B J$ inhibits the activation of the $N F-\kappa B$ signaling pathway in macrophages in vitro. It has been shown that bacterial LPS regulates the expression of pro-inflammatory cytokines through the NF- $\kappa$ B signaling pathway (29). Thus, we hypothesized that $\mathrm{XBJ}$ may modify pro-inflammatory cytokine secretion through the $\mathrm{NF}-\kappa \mathrm{B}$ signaling pathway. As the concentration of $50 \mathrm{mg} / \mathrm{ml}$ of XBJ effectively suppressed the secretion of IL- $1 \beta$ or TNF $\alpha$, we used this sample to analyze the activation status of the $\mathrm{NF}-\kappa \mathrm{B}$ signaling pathway. As is already known, NF- $\kappa \mathrm{B}$ dimers are inhibited by $\mathrm{I} \kappa \mathrm{B}(\alpha, \beta$ or $\varepsilon$ ) in the cytoplasm, while the phosphorylation of $\mathrm{I} \kappa \mathrm{B}$ results in $\mathrm{NF}-\kappa \mathrm{B}$ nuclear translocation and activation (30). We detected the phosphorylation status of $\mathrm{I} \kappa \mathrm{B}$, and found that pre-treatment with XBJ decreased the phosphorylation levels of $\mathrm{I} \kappa \mathrm{B} \alpha$ by $69.8 \%$ ( $\mathrm{p}=0.0297$ ) [Fig. $5 \mathrm{~A}$ (top panel) and B]. By contrast, the levels of unphosphorylated $\mathrm{I} \kappa \mathrm{B} \alpha$ were increased by 2.56 -fold $(\mathrm{p}=0.0142)$ [Fig. 5A (middle panel) and C]. Additionally, the protein levels of p65, a subunit of $\mathrm{NF}-\kappa \mathrm{B}$, were decreased by $76.6 \%$ in the nuclear extracts of the XBJ-pre-treated cells upon LPS stimulation (Fig. 5D and $\mathrm{E})$. These results suggest that $\mathrm{XBJ}$ inhibits $\mathrm{NF}-\kappa \mathrm{B}$ signaling pathway transduction induced by LPS.

\section{Discussion}

In the present study, we demonstrated that XBJ inhibits the activation of the NF- $\kappa \mathrm{B}$ signaling pathway induced by LPS, leading to a decrease in the release of pro-inflammatory cyto- 
kines. Considering the inhibitory effect of pro-inflammatory cytokines on Arap1 expression (22), our data may partly explain why pre-treatment with XBJ promotes Arap1 expression in rats during HS and thus attenuates hypotension.

It has been established that Ang II levels are increased upon heat stress (31); Ang II is associated with cardiovascular diseases, such as hypertension (32). In the current study, we found that Ang II levels in the serum and myocardial tissue were increased during HS. Considering the vasoconstrictor effect of Ang II, blood pressure should be elevated. However, arterial pressure was markedly decreased during HS. Although pre-treatment with XBJ had no obvious effect on Ang II levels, XBJ alleviated the decrease in blood pressure. These data indicated that HS reduced Ang II signal transduction following the elevation of blood pressure. Ang II, the major determinant of arterial pressure and volume homeostasis in mammals, mainly exerts its function through action on AT1 receptor $(33,34)$. We therefore examined the AT1 receptor, and the results revealed that AT1 surface expression was markedly inhibited during HS, which may explain why Ang II signal transduction was blocked. Furthermore, XBJ greatly improved AT1 receptor membrane trafficking.

Following the binding of ligands, the AT1 receptor is internalized through caveolae and clathrin-coated vesicles, which are then trafficked to endosomes (35-38). An increasing number of studies has revealed that the carboxyl terminal region of the AT1 receptor is tightly associated with receptor phosphorylation $(39,40)$, internalization $(41,42)$ and desensitization $(43)$. Subsequently, a novel protein termed Arap1 was found to specifically bind the carboxyl terminal region of the AT1 receptor using the yeast two-hybrid system, and was shown to play an essential role in receptor trafficking and recycling (20). Given that Arap1 accelerates receptor trafficking and recycling following ligand-induced receptor internalization, Arap1 may be significantly involved in the regulation of Ang II-mediated processes. In this study, we found that Arap1 expression was significantly inhibited druing HS; however, pre-treatment with XBJ attenuated this effect. These data suggest that pre-treatment with XBJ promotes Arap1 expression, which increases AT1 surface expression and re-sensitizes the cells (following exposure to Ang II), thus leading to enhanced Ang II signal transduction.

In rats with sepsis induced by LPS injection, plasma Ang II concentrations have been shown to be markedly increased (44); however, Arap1 expression was significantly inhibited, which was suggested to account for the hyporesponsiveness to Ang II (22). The inhibition of the IL-1 receptor has been shown to attenuate arterial hypotension in rats suffering from HS (14). Our previous study established that pre-treatment with XBJ markedly decreased the secretion of pro-inflammatory cytokines, including IL-1 $\beta, \mathrm{TNF} \alpha$ and IL-6 in rats suffering from HS (23). In this study, we also observed similar inhibitory effects of XBJ on cytokine expression in LPS-stimulated macrophages in vitro. Recently, a study demonstrated that Arap1 expression was markedly downregulated in cultured cells in the presence of pro-inflammatory cytokines (22). As a result, we hypothesized that XBJ may promote Arap1 expression by inhibiting the secretion of pro-inflammatory cytokines. Heat stress can increase intestinal permeability, leading to the translocation of bacteria and/or endotoxins into the circulation, which initiates inflammation and subsequent pro-inflammatory cytokine release $(5,6)$. LPS binds to its pattern recognition receptor, Toll like receptor 4 (TLR4), which then activates the $\mathrm{NF}-\kappa \mathrm{B}$ signaling pathway through a series of cascade events, leading to pro-inflammatory cytokine expression (29). NF-кB is considered to be an important mediator of inducible transcription in the immune system (45). Excessive stimulation of the immune system with LPS results in hypotension and septic shock (46). In this study, using an in vitro cell model, we observed that XBJ inhibited NF- $\kappa \mathrm{B}$ activation in LPS-stimulated macrophages. Our results were consistent with those of a recent study which demonstrated that the components of XBJ, including senkyunolide I, paeoniflorin, Danshensu, safflower yellow A, oxypaeoniflorin and benzoylpaeoniflorin, had an inhibitory effect against $\mathrm{NF}-\kappa \mathrm{B}$ and cytokine expression (24). Therefore, the anti-inflammatory effects of XBJ mainly depend on the inhibitory effects on NF- $\kappa \mathrm{B}$.

Taken together, we provide evidence that XBJ attenuates hypotension during HS through the upregulation of Arap1. The mechanisms underlying these effects may be due to the ability of XBJ to inhibit cytokine expression through the $\mathrm{NF}-\kappa \mathrm{B}$ signaling pathway. However, $\mathrm{XBJ}$ is a complex mixture of which complex drug composition causes adverse drug reactions (47). Hence, the effective components should be purified and screened to further study their synergistic mechanisms by network pharmacology.

\section{References}

1. Knochel JP: Disorders due to heat and cold. In: Textbook of Medicine. Wyngaarden JB and Smith LH (eds). Saunders, Philadelphia, pp2304-2306, 1985.

2. Semenza JC, Rubin $\mathrm{CH}$, Falter $\mathrm{KH}$, et al: Heat-related deaths during the July 1995 heat wave in Chicago. N Engl J Med 335: 84-90, 1996.

3. Robine JM, Cheung SL, Le Roy S, et al: Death toll exceeded 70,000 in Europe during the summer of 2003. C R Biol 331: 171-178, 2008.

4. Leon LR, Blaha MD and DuBose DA: Time course of cytokine, corticosterone, and tissue injury responses in mice during heat strain recovery. J Appl Physiol (1985) 100: 1400-1409, 2006.

5. Lu KC, Wang JY, Lin SH, Chu P and Lin YF: Role of circulating cytokines and chemokines in exertional heatstroke. Crit Care Med 32: 399-403, 2004.

6. Bouchama A, Ollivier V, Roberts G, et al: Experimental heatstroke in baboon: analysis of the systemic inflammatory response. Shock 24: 332-335, 2005.

7. Bouchama A, Hammami MM, Al Shail E and De Vol E: Differential effects of in vitro and in vivo hyperthermia on the production of interleukin-10. Intensive Care Med 26: 1646-1651, 2000.

8. Bouchama A, al-Sedairy S, Siddiqui S, Shail E and Rezeig M: Elevated pyrogenic cytokines in heatstroke. Chest 104: 1498-1502, 1993.

9. Hammami MM, Bouchama A, Al-Sedairy S, et al: Concentrations of soluble tumor necrosis factor and interleukin-6 receptors in heatstroke and heatstress. Crit Care Med 25: 1314-1319, 1997.

10. Hashim IA, Al-Zeer A, Al-Shohaib S, Al-Ahwal M and Shenkin A: Cytokine changes in patients with heatstroke during pilgrimage to Makkah. Mediators Inflamm 6: 135-139, 1997.

11. Bouchama A and Knochel JP: Heat stroke. N Engl J Med 346: 1978-1988, 2002.

12. Bouchama A, Roberts G, Al Mohanna F, et al: Inflammatory, hemostatic, and clinical changes in a baboon experimental model for heatstroke. J Appl Physiol (1985) 98: 697-705, 2005.

13. Lin MT, Kao TY, Jin YT and Chen CF: Interleukin-1 receptor antagonist attenuates the heat stroke-induced neuronal damage by reducing the cerebral ischemia in rats. Brain Res Bull 37: 595-598, 1995. 
14. Lin MT, Liu HH and Yang YL: Involvement of interleukin-1 receptor mechanisms in development of arterial hypotension in rat heatstroke. Am J Physiol 273: H2072-H2077, 1997.

15. Cumming AD, Driedger AA, McDonald JW, et al: Vasoactive hormones in the renal response to systemic sepsis. Am J Kidney Dis 11: 23-32, 1988.

16. Hilgenfeldt U, Kienapfel G, Kellermann W, Schott R and Schmidt M: Renin-angiotensin system in sepsis. Clin Exp Hypertens A 9: 1493-1504, 1987.

17. Benedict CR and Rose JA: Arterial norepinephrine changes in patients with septic shock. Circ Shock 38: 165-172, 1992.

18. Castrop H: Angiotensin receptor-associated proteins: local modulators of the renin-angiotensin system. Pflugers Arch 465 111-119, 2013.

19. Kai H, Griendling KK, Lassègue $\mathrm{B}$, et al: Agonist-induced phosphorylation of the vascular type 1 angiotensin II receptor. Hypertension 24: 523-527, 1994.

20. Guo DF, Chenier I, Tardif V, Orlov SN and Inagami T: Type angiotensin II receptor-associated protein ARAP1 binds and recycles the receptor to the plasma membrane. Biochem Biophys Res Commun 310: 1254-1265, 2003.

21. Doblinger E, Höcherl K, Mederle K, et al: Angiotensin AT1 receptor-associated protein Arapl in the kidney vasculature is suppressed by angiotensin II. Am J Physiol Renal Physiol 302 : F1313-F1324, 2012.

22. Mederle K, Schweda F, Kattler V, et al: The angiotensin II AT1 receptor-associated protein Arap1 is involved in sepsis-induced hypotension. Crit Care 17: R130, 2013.

23. Chen $\mathrm{Y}$, Tong $\mathrm{H}$, Zhang $\mathrm{X}$, et al: Xuebijing injection alleviates liver injury by inhibiting secretory function of Kupffer cells in heat stroke rats. J Tradit Chin Med 33: 243-249, 2013.

24. Jiang M, Zhou M, Han Y, et al: Identification of NF- $\mathrm{BB}$ inhibitors in Xuebijing injection for sepsis treatment based on bioactivity-integrated UPLC-Q/TOF. J Ethnopharmacol 147: 426-433, 2013

25. Chen SH, Chang FM, Niu KC, Lin MY and Lin MT: Resuscitation from experimental heatstroke by estrogen therapy. Crit Care Med 34: 1113-1118, 2006.

26. Chen CM, Hou CC, Cheng $\mathrm{KC}$, et al: Activated protein $\mathrm{C}$ therapy in a rat heat stroke model. Crit Care Med 34: 1960-1966, 2006.

27. Livak KJ and Schmittgen TD: Analysis of relative gene expression data using real-time quantitative PCR and the 2(-Delta Delta (CT)) method. Methods 25: 402-408, 2001.

28. Ohtani R, Ohashi Y, Muranaga K, Itoh N and Okamoto $\mathrm{H}$ Changes in activity of the renin-angiotensin system of the rat by induction of acute inflammation. Life Sci 44: 237-241, 1989.

29. Rodriguez-Fernandez M, Grosman B, Yuraszeck TM, et al: Modeling the intra- and extracellular cytokine signaling pathway under heat stroke in the liver. PLoS One 8: e73393, 2013.

30. Gilmore TD: Introduction to NF-kappaB: players, pathways, perspectives. Oncogene 25: 6680-6684, 2006.

31. Watanabe T, Miyoshi M and Imoto T: Angiotensin II: its effects on fever and hypothermia in systemic inflammation. Front Biosci 9: 438-447, 2004.
32. Paradis P, Dali-Youcef N, Paradis FW, Thibault G and Nemer M: Overexpression of angiotensin II type I receptor in cardiomyocytes induces cardiac hypertrophy and remodeling. Proc Natl Acad Sci USA 97: 931-936, 2000.

33. Hall JE: Control of sodium excretion by angiotensin II: intrarenal mechanisms and blood pressure regulation. Am J Physiol 250: R960-R972, 1986.

34. Hall JE and Granger JP: Adenosine alters glomerular filtration control by angiotensin II. Am J Physiol 250: F917-F923, 1986.

35. Hunyady L, Catt KJ, Clark AJ and Gáborik Z: Mechanisms and functions of AT(1) angiotensin receptor internalization. Regul Pept 91: 29-44, 2000.

36. Gaborik Z, Szaszák M, Szidonya L, et al: Beta-arrestin- and dynamin-dependent endocytosis of the AT1 angiotensin receptor. Mol Pharmacol 59: 239-247, 2001

37. Perry SJ and Lefkowitz RJ: Arresting developments in heptahelical receptor signaling and regulation. Trends Cell Biol 12: 130-138, 2002.

38. Tohgo A, Pierce KL, Choy EW, Lefkowitz RJ and Luttrell LM: beta-Arrestin scaffolding of the ERK cascade enhances cytosolic ERK activity but inhibits ERK-mediated transcription following angiotensin AT1a receptor stimulation. J Biol Chem 277: 9429-9436, 2002.

39. Smith RD, Baukal AJ, Zolyomi A, et al: Agonist-induced phosphorylation of the endogenous AT1 angiotensin receptor in bovine adrenal glomerulosa cells. Mol Endocrinol 12: 634-644, 1998.

40. Smith RD, Hunyady L, Olivares-Reyes JA, et al: Agonist-induced phosphorylation of the angiotensin AT1a receptor is localized to a serine/threonine-rich region of its cytoplasmic tail. Mol Pharmacol 54: 935-941, 1998.

41. Conchon S, Peltier N, Corvol P and Clauser E: A noninternalized nondesensitized truncated AT1A receptor transduces an amplified ANG II signal. Am J Physiol 274: E336-E345, 1998.

42. Hunyady L, Bor M, Balla T and Catt KJ: Identification of a cytoplasmic Ser-Thr-Leu motif that determines agonist-induced internalization of the AT1 angiotensin receptor. J Biol Chem 269: 31378-31382, 1994.

43. Tang H, Guo DF, Porter JP, Wanaka Y and Inagami T: Role of cytoplasmic tail of the type $1 \mathrm{~A}$ angiotensin II receptor in agonist- and phorbol ester-induced desensitization. Circ Res 82: 523-531, 1998.

44. Hagiwara S, Iwasaka H, Matumoto S, Hidaka S and Noguchi T: Effects of an angiotensin-converting enzyme inhibitor on the inflammatory response in in vivo and in vitro models. Crit Care Med 37: 626-633, 2009.

45. Ghosh S and Hayden MS: New regulators of NF-kappaB in inflammation. Nat Rev Immunol 8: 837-848, 2008.

46. Watters TM, Kenny EF and O'Neill LA: Structure, function and regulation of the Toll/IL-1 receptor adaptor proteins. Immunol Cell Biol 85: 411-419, 2007.

47. Li T: Avoiding adverse drug reactions to Chinese medicine injections. J Evid Based Med 3: 44-49, 2010. 